continue to be an uncomfortable and probably unheeded message for those donors and agencies who exhort the governments of developing countries to make their economies more competitive and to import market principles into their health sectors.

ANTHONY M DE L COSTELLO Senior Lecturer in International Child Health, Centre for International Child Health, Institute of Child Health,

London WCIN 1EH

TARIQ IQBAL BHUTTA Professor of Paediatrics,

King Edward College

Mayo Hospital,

Lahore,

Pakistan
World Health Organisation. The rational use of drugs in the management of acute diarrhoea in children. Geneva: WHO, 1990.

Saunders P. Pakistan: misuse of drugs for childhood illnesses. Lancet 1991;338:438.

Lerman SL, Shepard DS, Cash RA. Treatment of diarrhoea in Indonesian children: what it costs and who pays for it. Lancet 1988 ;ii:651-4.

Chetley A. A healthy business? World health and the pharmaceutical industry. London: Zed Books, 1990.

5 Goodburn E, Mattosinho S, Mongi P, Waterston T. Management of childhood diarrhoea by pharmacists and parents: is Britain lagging behind the Third World? BMf 1991;302:440-2. Bhutra TI, Tahir KI. Loperamide poisoning in children. Lancet 1990:335:363.

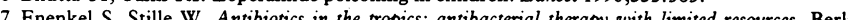
Springer Verlag, 1988.

8 Pal SC. Epidemic bacillary dysentery in West Bengal, India. Lancet 1984;i:1462.

9 Hardon AP. Confronting ill health. Medicines, self care and the poor in Manila (dissertation). Amsterdam: University of Amsterdam, 1990.

0 Molla AM, Molla A, Nath SK, Khatun M. Food based oral rehydration salt solution for acute childhood diarrhoea. Lancet 1989;ii:429-31.

11 Hardon A, van der Geest S, Geerling H, le Grand A. The provision and use of drugs in developing countries. Review of studies and annotated bibliography. Amsterdam: Het Spinhuis Publishers, 1991

12 van der Geest S, Hardon AP, Whyte SR. Planning for essential drugs: are we missing the cultural dimension? Health Policy and Planning 1990;5:182-5.

\title{
Voice after laryngectomy
}

\section{"Speech buttons" could be more widely used}

Most patients are struck dumb, at least temporarily, when told that they have cancer, but for those with carcinoma of the larynx this may prove to be more than a mere figure of speech. In many the voice has already deteriorated, and over three quarters of those who have a laryngectomy fail to develop adequate oesophageal speech. ${ }^{12}$ Inability to communicate often makes these patients totally unemployable. ${ }^{3}$ This, together with the presence of a permanent tracheostome and their altered body image, may contribute to a deep sense of isolation and depression. Though some make no complaint, all find the experience intensely disturbing. For many the disability is long lasting as overall five year survival is about $80 \%$. $^{4}$

Fortunately, many patients with early disease can be cured with radiotherapy alone and their voice quality restored to its premorbid state..$^{5-7}$ By contrast, some fail to respond favourably to treatment or develop a recurrence after radiotherapy. Others present with advanced disease, and for these unlucky patients total laryngectomy provides the only hope of long term survival. ${ }^{89}$ Perhaps the greatest management problem is the choice of treatment for those with locally advanced $\left(\mathrm{T}_{3} \mathrm{~N}_{0} \mathrm{M}_{0}\right.$ ) disease. ${ }^{10}$ In this group of patients survival rates for primary radiotherapy have been almost comparable but are inferior to those for surgery. ${ }^{11-13}$ Perhaps unsurprisingly, up to one in five patients choose radiotherapy, even though it is therapeutically inferior, to preserve their voice. ${ }^{14}$

Voice conservation can be achieved with surgical treatment for a small minority. Cordectomy and vertical or horizontal partial laryngectomy may be as effective as radiotherapy in controlling disease that is still at an early stage and well localised. This form of surgery does not always eliminate the need for tracheostomy, and the quality of phonation afterwards is rarely good, except after supraglottic laryngectomy. ${ }^{15}$ Furthermore, all these procedures are fraught with complications, not the least of which are aspiration pneumonia and recurrence due to inadequate resection. Over the years total laryngectomy has therefore proved to be the single most reliable and oncologically sound procedure. Many surgeons regard this as the only practical alternative to radiotherapy.

The traditional rehabilitative approach after surgery is for speech therapists to work intensively over several weeks with a patient who has just undergone laryngectomy. They teach them how to ingest air into the oesophagus, regurgitate it in a controlled manner to produce sound, and then modulate and articulate it into comprehensible speech. As only about $80 \mathrm{ml}$ of air can be held in the oesophagus speech has to be delivered in a series of staccato phrases punctuated by gulps of air. A few patients become remarkably fluent - some even singbut most achieve little more than a whisper. Those who have remained silent have been equipped with vibrating devices, which they have held in contact with the neck and activated while mouthing words. ${ }^{16}$ Their utterances, often unintelligible, are frequently likened to those of extraterrestrial, science fiction creatures, a source of constant amusement to young children but a continuing source of misery for the victim.

Several factors determine whether or not patients acquire a satisfactory oesophageal voice. Detailed analyses of the functional anatomy of the reconstructed pharynx have concentrated mainly on where the sound is produced: the pharyngo-oesophageal segment. Stricture, spasm, and hypotonicity of this segment are all associated with poor speech and are readily shown by videofluoroscopy. In some patients surgery may overcome these problems. This takes the form of flap reconstructions for strictures or myotomy to decrease spasm. Hypotonicity may occasionally be rectified merely by digital pressure on the front of the neck during phonation. ${ }^{17}$ Attributing poor oesophageal speech to a patient's psychological, sociological, or intellectual limitations is no longer acceptable.

All this takes time, but a few readily identifiable patients (for example, those who have undergone salvage for advanced disease) have relatively little of this valuable commodity left. Worse still, extensive resections of the pharynx, or oesophagus in addition to the larynx, reconstructed with stomach, colon, or myocutaneous flaps rarely allow the patient to speak well no matter how much effort is put into speech therapy.

Fortunately the surgical management of such patients and those who are dissatisfied with the quality of their oesophageal voice has changed radically in the past decade. Although primary and secondary tracheo-oesophageal puncture and the formation of fistulas through which patients can shunt air into their pharynx are far from new, ${ }^{18} 19$ the techniques for preventing unwanted salivary leaks and aspiration certainly are. A wide variety of silicone, flanged, valved stents are now available for insertion into the fistula. The patient merely blocks his or her tracheostome with a thumb and injects into the pharynx just as much air as is necessary for conversation. Even better, recently developed stomal valves automatically 
divert the air flow through the artificial fistula during forced expiration. This leaves the patients free to gesticulate with both hands to make their points more forcibly. Good functional results with these speech buttons have been reported from all over the world, and long term complications seem to be relatively few. ${ }^{20-22}$ Many patients who have been unable to acquire oesophageal speech have been successfully treated: fluency rates of $90 \%$ have been achieved. ${ }^{18}$

The success of these valves has been so well publicised that the relations of many patients in the United Kingdom ask why so few have had speech buttons fitted. Cost is not a limitation-it is similar to that of a routine intermediate procedure in ear, nose, and throat surgery, and the cost of annual maintenance is no more than $£ 150-200$. The reason probably lies more in the conservatism of British surgeons and past experience of unplanned and uncontrolled pharyngeal fistulas complicating laryngectomy. No doubt primary puncture at the time of laryngectomy will receive the same circumspect approach, though it is being performed in a few British centres. Dedicated and well trained auxiliary staff are necessary to provide a speech button service, but no good reason exists why this cannot be realised in any centre performing a reasonable amount of surgery for cancer of the head and neck.

MICHAEL GLEESON

Reader in Otolaryngology,

Guy's Hospital,

London SE1 9RT
Harwood AR, Rawlinson $E$. The quality of life of patients following treatment for laryngeal cancer. Int f Radiat Oncol Biol Phys 1983;9:335-8.

Schaefer SD, Johns DF. Attaining functional oesophageal speech. Archives of Otolaryngology 1982;108:647-9.

Gilchrist AG. Rehabilitation after laryngectomy. Acta Otolaryngol (Stockh) 1973;75:511-8.

4 Berry RJ. Radiotherapy and chemotherapy. In: Edels Y, ed. Laryngectomy: diagnosis and rehabilitation. London: Croom-Helm, 1983:18-36.

5 Kelly MD, Hahn SS, Spaulding CA, Kersh CR, Constable WC, Cantrell RW. Definitive radiotherapy in the management of stage I and II carcinomas of the glottis. Ann Otol Rhinol Laryngol 1989;98:235-9.

6 Harwood AR, Beale FA, Cummings BJ, Keane TJ, Payne DG, Rider WD. Management of early supraglottic laryngeal carcinoma by irradiation with surgery in reserve. Archives of Otolaryngology 1983;109:583-5.

7 Stoicheff ML. Voice following radiotherapy. Laryngoscope 1975;85:608-18.

8 Bosch A, Kademan MT, Frias ZC, Caldwell WL. Failures after irradiation in early vocal cord cancer. Laryngoscope 1978;88:2017-21.

9 Kirchner JA, Owen JR. Five hundred cancers of the larynx and pyriform sinus. Results of treatment by radiation and surgery. Laryngoscope 1977;87:1288-303.

10 Olofsson J, Lord IJ, Van Nostrand AWP. Vocal cord fixation in laryngeal carcinoma. Acta Otolaryngol (Stockh) 1973;75:496-510.

11 Yuen A, Medina JE, Goepfert H, Fletcher G. Management of stage T3 and T4 glottic carcinomas. Am $\mathcal{F}$ Surg 1984;148:467-72.

12 Kaplan MJ, Johns ME, Clark DA, Cantrell RW. The roles of surgery and irradiation. Cancer 1984;53:2641-8.

13 Harwood AR, Bryce DP, Rider WD. Management of T, glottic cancer. Archives of Otolaryngology 1980;106:697-9.

14 McNeil BJ, Weichselbaum R, Pauker SG. Speech and survival. Tradeoffs between quality and quantity of life in laryngeal cancer. $N$ Engl $\mathcal{F}$ Med 1981;305:982-7.

15 Moore GP. Voice problems following limited surgical excision. Laryngoscope 1975;85:619-25.

16 Goode RL. Artificial laryngeal devices in post-laryngectomy rehabilitation. Laryngoscope 1975;85:677-89.

17 McIvor J, Evans PF, Perry A, Cheesman AD. Radiological assessment of post laryngectomy speech. Clin Radiol 1990;41:312-6.

18 Singer MI, Blom ED. An endoscopic technique for restoration of voice after laryngectomy. Ann Otol Rhinol Laryngol 1980;89:529-33.

19 Hamaker RC, Singer MI, Blom ED, Daniels HA. Primary voice restoration at laryngectomy. Archives of Otolaryngology 1985;111:182-6.

20 Wetmore SJ, Krueger K, Blessing ML. Long term results of the Blom-Singer speech rehabilitation procedure. Archives of Otolaryngology 1985;111:106-9.

21 Ward PH, Andrews JC, Mickel RA, Hanson DG, Monahan GP. Complications of medical and surgical approaches to voice restoration after total laryngectomy. Head and Neck Surgery 1988;10:124-8

22 Perry A, Cheesman AD, McIvor J, Chalton R A British experience of surgical voice restoration techniques as a secondary procedure following total laryngectomy. I Laryngol Otol 1987;101:155-63.

\section{Failed hip replacements}

\section{All replacements will fail eventually; revision needs to be done by specialists}

Total hip replacement is big business. As many as 40000 of these operations are performed each year in the United Kingdom, and $98 \%$ of patients are said to be satisfied with the result. After early reports of the prosthesis loosening, ${ }^{1}$ much attention is now paid to the longevity of replacement hips. Results vary widely, with failure rates of up to $24 \%$ being reported. ${ }^{2}$ Once a primary hip replacement has failed it needs to be revised, but revision arthroplasty is more time consuming, more complicated, and more expensive than the primary procedure. ${ }^{3}$ Some practices claim that over half of all total hip replacements are revisions and that workload is likely to increase. $^{4}$

Hip replacements fail for several reasons. About $5 \%$ of patients have a serious complication associated with surgery, though most complications resolve themselves or are correctable. ${ }^{5}$ The main problem is more long term and is simply the failure of the components to remain fixed to bone owing to fractured cement, ${ }^{6}$ loss of bone stock, ${ }^{7}$ and the wear products produced by the friction between the metal femoral component and the high density polyethylene acetabulum. ${ }^{8}$

Because most hip replacements will fail given time the right patient must be chosen for the operation in the first place. Those over 60 years old are likely to place less strain on the hip and thus improve its lifespan. ${ }^{9}$ Younger patients and those who are overweight do not do so well. ${ }^{10}$

The surgeon can do much to delay the onset of problems. Surgical technique is vital to the success of the procedure, particularly the use of advanced, pressurising, cementing techniques. ${ }^{11}$ The design of the component is also important, clinical experience suggesting that femoral components with rounded edges and a rectangular cross section give better results. ${ }^{12}$ Thicker acetabular components also tend to do better than thinner ones. ${ }^{13}$ The risk of deep infection can be minimised by the prudent use of antibiotics and clean air operating theatres, such that the unacceptably high infection rates of early studies ${ }^{14}$ can now be reduced to less than $1 \%$ for primary procedures. ${ }^{15}$

The method of fixing the prosthetic components to bone may also influence the performance of the replacement. Some centres now favour uncemented replacements instead of the traditional cemented fixation. The idea that bone should integrate precisely with the components without the need for any grout has attractions, but prosthetic integration is actually very limited ${ }^{16}$ and the results are not universally convincing. There is therefore now a trend towards use of the hybrid hip replacement, cement being used to secure the femoral component while the acetabulum is seated in a press fit, uncemented manner. Initial results are favourable. ${ }^{17}$

Despite all these efforts, total hip arthroplasties do eventually fail, and the problem of the revision procedure has to be addressed. The commonest form of revision replacement in the United Kingdom is the conversion of a failed cemented primary hip replacement to a cemented revision. The frequency of early postoperative complications after revision arthroplasty may be twice that after primary intervention..$^{18}$ Also though the early results of revision surgery can be nearly as good as results for the primary operation, ${ }^{19}$ the failure rate of the revision replacement is much higher ${ }^{20}$-occasionally as 